\title{
REVIEW OF EFFECTS OF FIBER CONTENT AND FIBER LENGTH ON THE MECHANICAL PROPERTIES OF BIOCOMPOSITES
}

\section{APARCHIT SHARMA}

Delhi Technological University, Bhawana Road, Shahbad Daulatpur Village, Rohini, Delhi, India

Rampant increase in the industrial activities in the developed and the developing nations, the emission of green house gases and the rapid degradation of non-renewable resources pose a threat to our planet's environmental stability. Biocomposites derived from the renewable resources such as plant fibre or animal wastes can prove to be much environmental friendly alternatives. Different processing parameters are responsible for making biocomposites capable of matching the standards set by the conventional petroleum based products. In this work, fibre content and fibre length of different natural fibres used and their effects on the mechanical properties of the biocomposites are recorded. KEYWORDS: Bicomposites, Processing Parameters, Fiber Content, Fiber Length \& Mechanical Properties
\end{abstract}

Received: Jun 08, 2020; Accepted: Jun 28, 2020; Published: Sep 12, 2020; Paper Id.: IJMPERDJUN20201192

\section{INTRODUCTION}

Environmental sustainability and stability are of paramount importance in these current times. Petroleum propelled by these growing consumer needs, is being utilized in colossal proportion. The non-biodegradability of the these synthetic plastics deplete the quality of the both land and water resources. This requires a drastic change in our manufacturing and material policies. There needs to be growing urgency to develop bio-based products and also devise novel methods to wean the industries off the persistent dependence on the fossil fuels. That is why Biocomposites are now attaining increased industrial interest to stop the mounting environmental pressure [1] (Faruk, 2012).

Biocomposite- a composite fabricated using biomaterial compounds with a natural fibre reinforcement as a raw material and bio-based matrix of the polymer as well [2] (Sarisini 2018). These natural fibres provide the stiffness and the strength to the composites. The other component of the biocomposites are the resins or the matrices used. The synthetic plastics are still prevalent in the industries but bio-based polymers are now starting to catch the eye of the industrialists. Polymers such as PolyLactic-acid (PLA), Poly-hydroxy-alkanoates (PHA), Poly-3 hydroxybutyrate (PHB), Poly-hydroxy-valerate etc are the biopolymers derived from renewable resources. Many processing techniques have been modified and novel fabricating methods have also been developed [3](Bajpai). The main aim of the development of these fabrication methods have always been to develop a defect free product that is as good as the ones manufactured using synthetic polymers.

This present work focuses solely on the biocomposites fabricated using the natural fibres and biopolymers. Also, the effect of different processing parameters namely fibre content and fibre length on the mechanical properties of biocomposite has been extensively covered in this current work. In order to see the effect of these variables on the biocomposite, we need to first introduce ourselves with the different processing parameters 
involved.

\section{Factors Affecting the Mechanical Properties of the Biocomposites}

From the initial stage of raw materials to the final stage of the complete product, different processing parameters play a significant role on the performance of the biocomposite. These factors are responsible for altering the mechanical as well as the thermal properties of the final product. Since this current work concerns only the mechanical properties, therefore following factors that are laid out are selected accordingly:

- Fibre Type

- Fibre Content

- $\quad$ Aspect Ratio

- Matrix

- Fibre-Matrix Interface

- Manufacturing Process

- Density

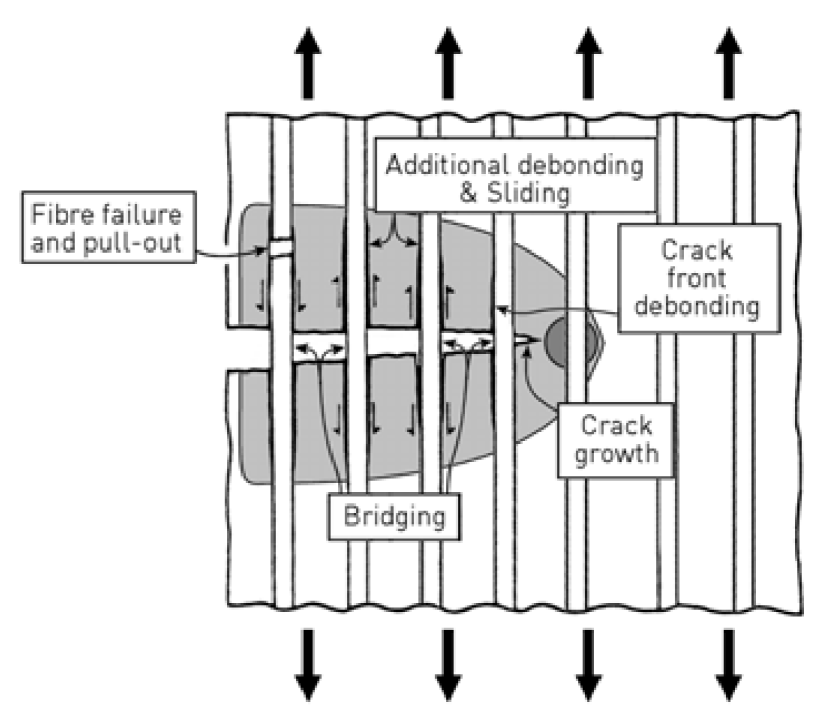

Figure 1: Processing Parameters.

Since this current is concerned with Fibre Content and Fibre Length (Aspect Ratio), the following sections shall elaborate on these parameters.

\section{Fiber Content}

Concentration of fibre content offer addition effects during the manufacturing of biocomposites. Increasing of fibre content beyond a certain threshold can lead to an uptick in mechanical properties such as tensile strength, young's modulus, flexural strength, flexural modulus and impact strength. This increase in the performance of the biocomposite is attributed to the increase in the quantity of the fibres at the fibre-matrix interface which leads to effective sharing of external stresses at the interface. Increased fibre content leads to adequate interlocking among the fibres and thus benefitting the biocomposite as a whole. On the one hand there is a possibility of increasing tensile strength with fibre loading, on the 
other hand, completely opposite trends have been witnessed to. This can be attributed to incompatibility between matrices and fibres, improper manufacturing process and fibre degradation [4] (Mittal, Chaudhary).

\section{Fiber Length}

Aspect ratio is defined as the ratio of the length of the natural fiber to its diameter. higher aspect ratio means higher fiber length, therefore the external stresses applied are transferred from the resin onto the entire length of the fiber, thereby preventing any possibility of fracture or cracks. if the fiber length is less than the critical length, then the stress transfer efficiency between the matrix and fiber will decrease because of the fiber pullout process, since it requires lesser energy[5] (ranganathan. n,). lower diameter of fibers also aid the enhancement of mechanical properties by decreasing the frequency of stress concentration defects which occur when a fiber has high cross-sectional area. also, fiber dispersion is more complete for small diameter fibers as compared to the larger ones.

\section{LITERATURE REVIEW}

With the aim to review the effects of fibre content and fibre length on the mechanical properties of the biocomposite, a literature review is presented in this chapter. The reason why fiber content and fiber length were selected because of lack of consolidated data present for both these parameters. Also, contrary to conventional belief, both these parameters do not necessarily show either an increasing or a decreasing trend. A case for a combined technical review of all the processing parameters can also be made which could be taken up in the subsequent reviews.

\section{Literature Review of Fiber Content}

- Mohanty et.al [6] studied the effect of reinforcing hemp fiber on the powdered cellulose acetate by varying the weight fraction of hemp fiber from $0 \%$ to $15 \%$ and finally to $30 \%$. The biocomposite using the reinforcing fiber and powdered acetate was fabricated using two processes: compression molding and extrusion followed by injection molding. The fiber content for both processes was varied from $0 \%$ to $30 \%$ and modulus of elasticity as well as flexural properties were determined using the United Calibration Corp. SFM-20 machine as per the ASTM D790 standard. It was observed that upon increasing the fiber content, the flexural strength and the modulus of elasticity showed an increase for both the process from $0 \%$ to $30 \%$.

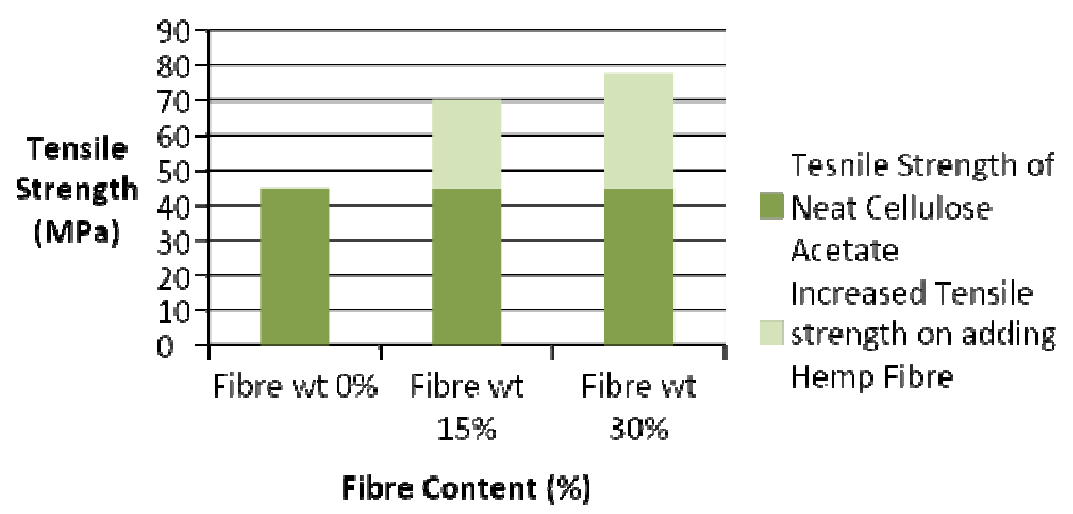

Figure 2: Effect of Reinforcement Fibre on Tensile Strength.

- Liu et.al [7] fabricated the biocomposite consisting of soy flour based bioplastic reinforced with Pineapple Leaf Fiber (PALF) using the Polyester amide glycidyl methacrylate (PEA-g-MEA) compatibilizer in the system. The 
flexural strength and the flexural modulus increased showed an increase of 3 to 15 times respectively from $0 \%$ fiber wt. to $30 \%$ fiber wt. The flexural properties also increased with the addition of the compatibilizer.

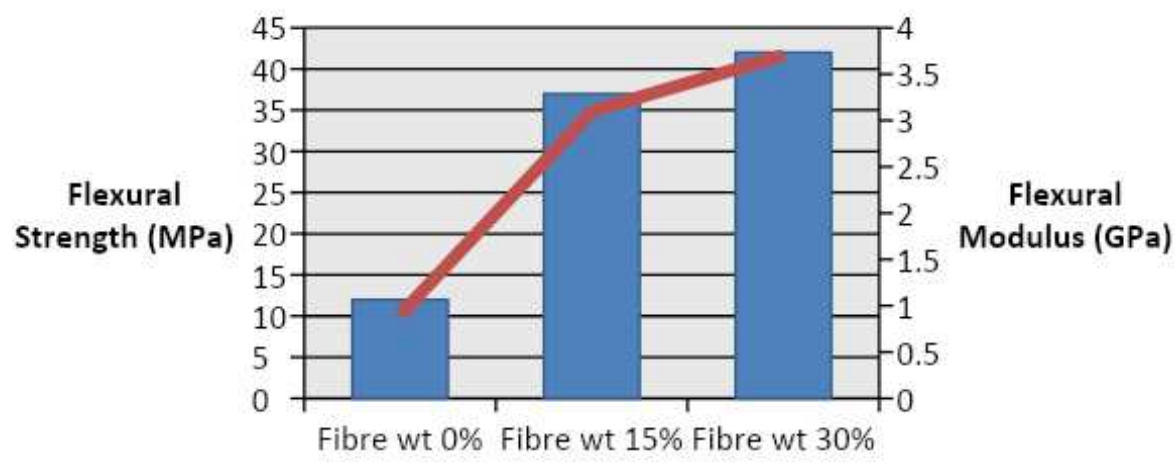

Fibre Content $(\%)$

Flexural Strength $=$ Flexural Modulus

Figure 3: Effect of PALF Fibre Content on Flexural Strength and Flexural Modulus.

- Swapan et.al [8] assessed improvement in the mechanical properties of the industrial hemp reinforced Poly(lactic acid) (PLA). The alkaline ( $5 \% \mathrm{Naoh})$ and silane treatments $(0.5 \mathrm{wt} \%$ of 3-(2-aminoethyl amino)propyl trimethoxy silane) were used separately on individual batches The young's modulus also exhibited the same trend with an increase from $3.5 \mathrm{GPa}$ at $0 \% \mathrm{wt}$ of fiber reinforcement to $8.5 \mathrm{GPa}$ at $30 \% \mathrm{wt}$, of alkaline treat hemp fibers.

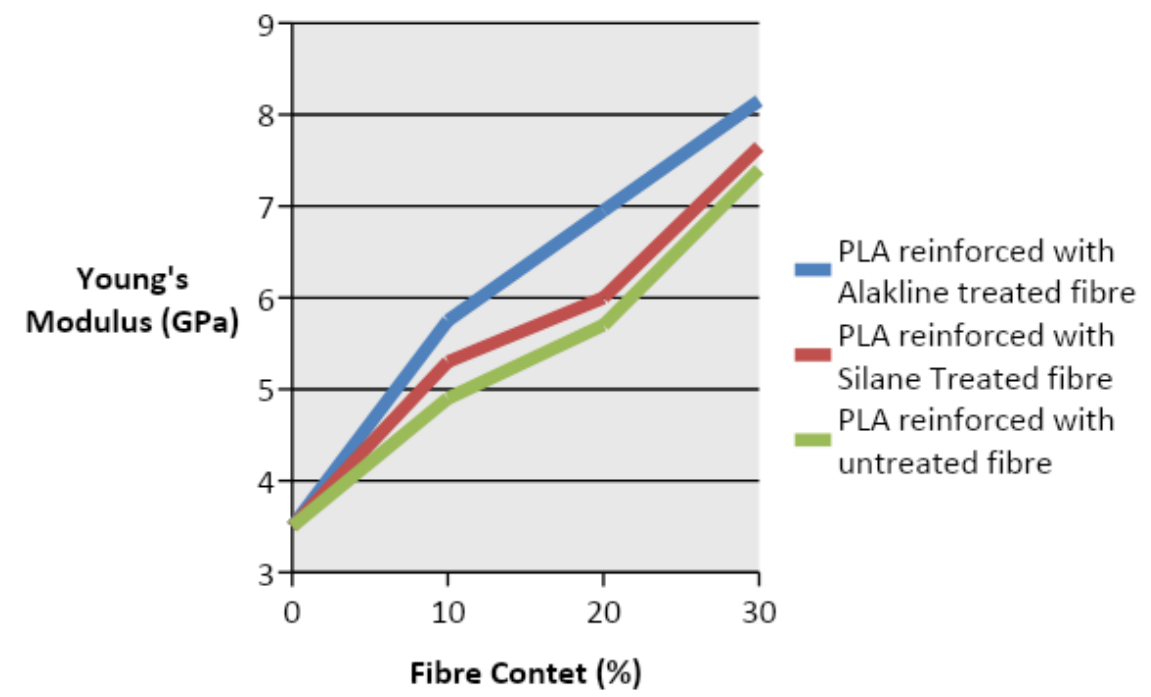

Figure 4: Effect of Fibre Content on Young's Modulus of Hemp Reinforced PLA.

- Mittal et.al [9] studied the effect of incorporation of PALF/Coir into epoxy resin in the form of a hybridized biocomposites and assessed the role played by increasing fiber content on the mechanical properties of the composites. The hand lay-up technique was employed to fabricate the laminar sheets of the biocomposite It was observed that upon incorporating the $0.2 \% \mathrm{~V}_{\mathrm{f}}(20 \%$ of total fibre volume) PALF into the coir/epoxy composites, the tensile strength increased from $12.34 \mathrm{MPa}$ to $22.97 \mathrm{MPa}$ 


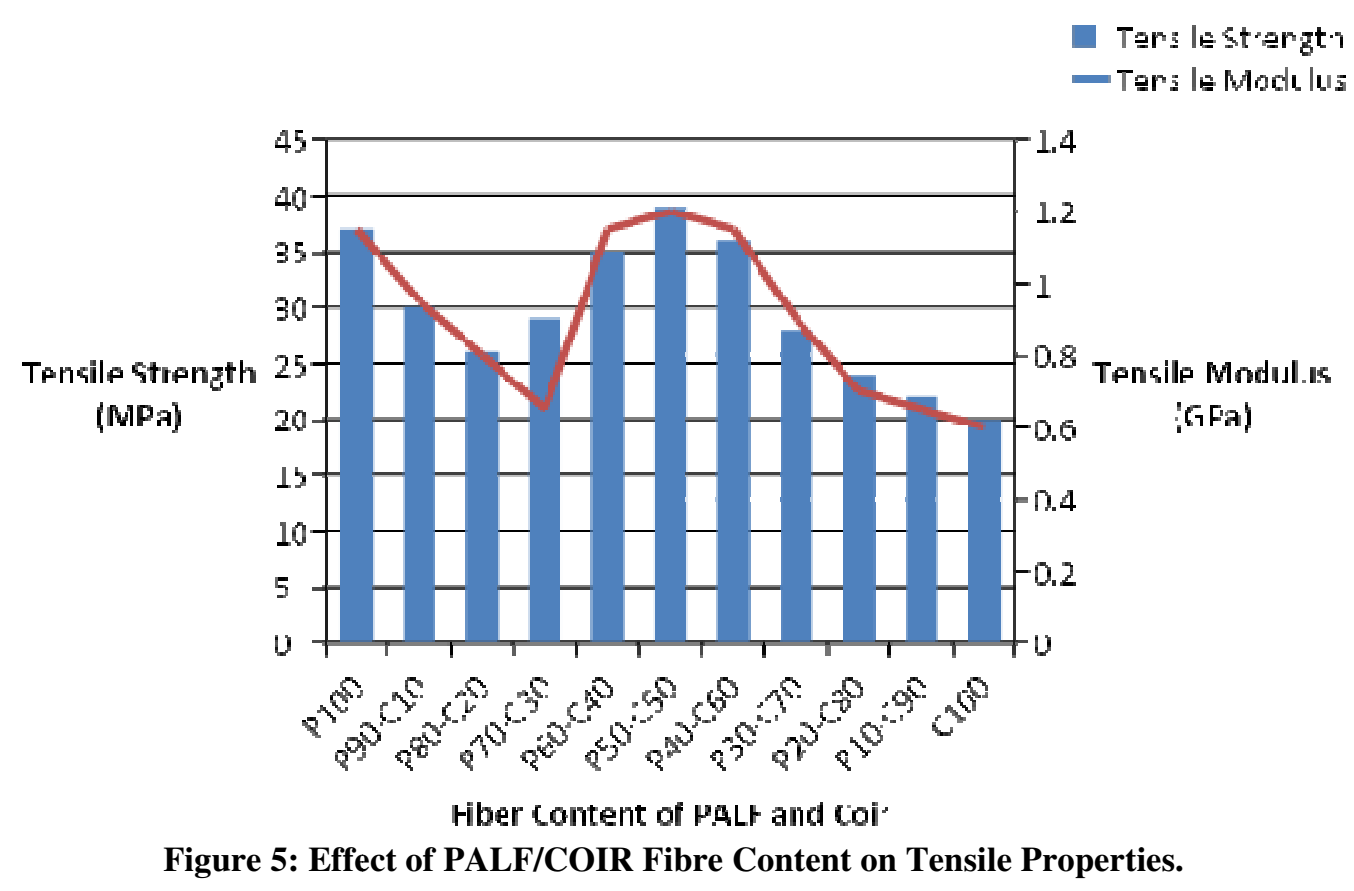

Literature Review on Fiber Length

- Naveen et.al [10] used coir fiber with epoxy resin to study the effect of fiber length on the mechanical properties of the composite. Polyester was added to the epoxy resin in order to increase the biodegradability of the composite. The composite was fabricated and then tested using universal testing machine as per the ASTM D638 standard. The tensile strength increased with increase of the fiber length. So did the tensile modulus. The increase can be attributed to optimum wetting of the fibers by the matix.

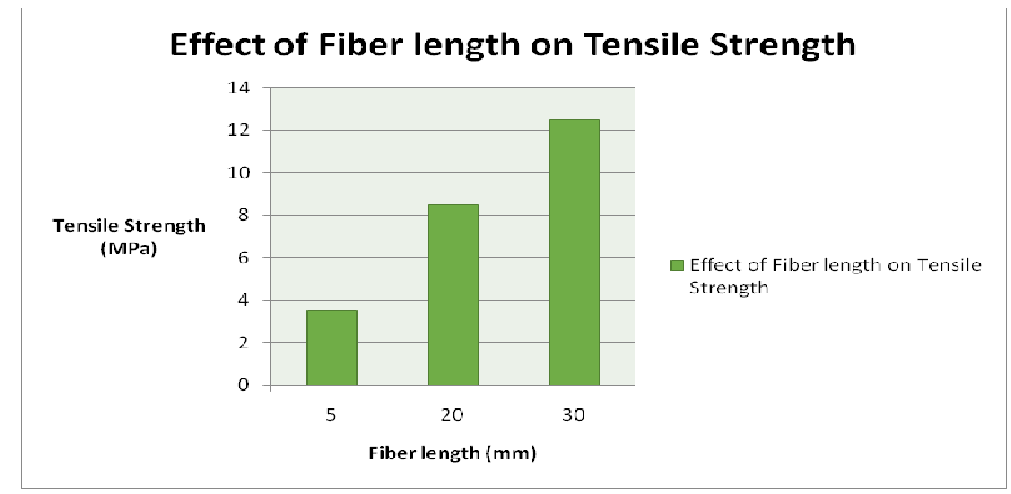

Figure 6: Effect of Fibre Length on Tensile Strength.

- Thirmizir et.al [11] fabricated the biocomposite using kenaf bast fibre reinforced on Maleated Poly (butylene succinate). The effect of the fibre length on the impact and flexural properties was investigated. In order to improve the interfacial adhesion of fibre and the matrix, a compatibilizer that is Maleic Anhydride (MA) was grafted onto the PBS using reactive mixing. The flexural strength was maximum and increased by $6.7 \%$ at $30 \mathrm{wt} \%$ of Kenaf Bast fibre loading with the addition of $10 \mathrm{~mm}$ fibre length. As for flexural modulus, there was slight increase in the modulus by the addition of $10 \mathrm{~mm}$ kenaf fibre accompanied by increase in flexural strength. 


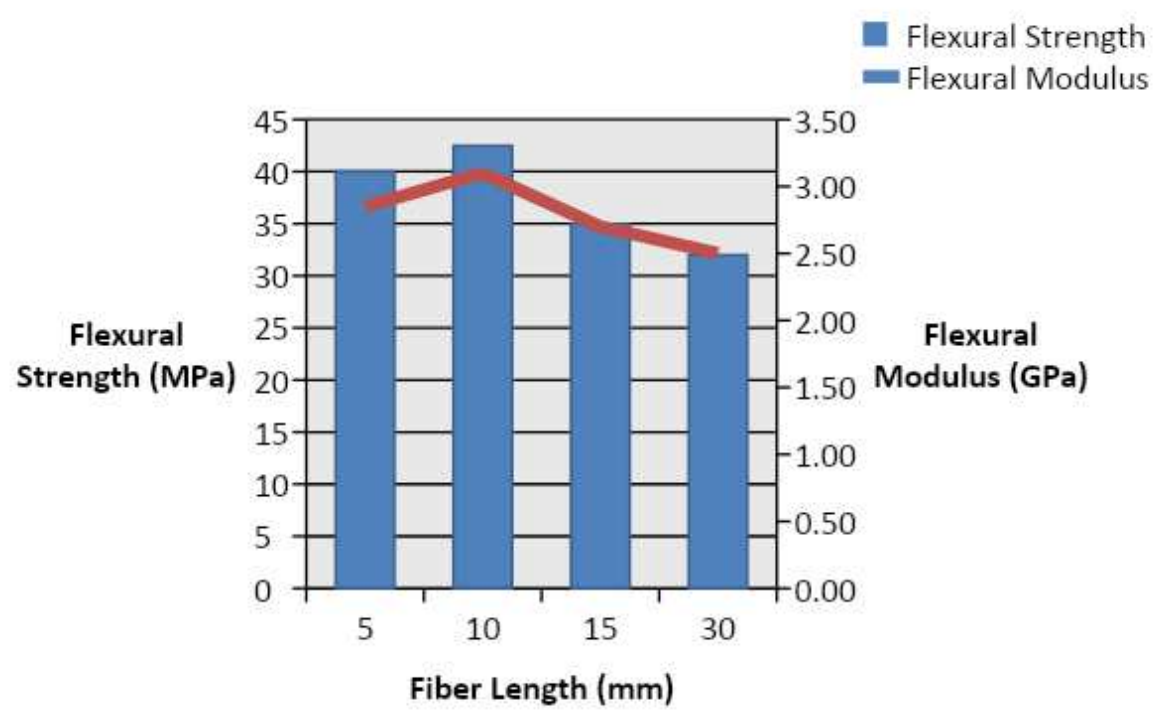

Figure 7: Effect of Fibre Length on Kenaf Fibre Reinforced PBS Composite.

- Sumaila et.al [12] investigated the effect of fibre length on the mechanical properties of randomly oriented short banana fibre and epoxy composites. Short banana fibres were used because of their biodegradability, low density, renewable nature, low cost and less abrasion to the tooling.They were further treated $5 \% \mathrm{NaOH}$ solution for $4 \mathrm{~h}$. The treated fibres were dried in the oven for $24 \mathrm{~h}$ at $105^{\circ} \mathrm{C}$ and cut into lengths of $5 \mathrm{~mm}, 10 \mathrm{~mm}, 15 \mathrm{~mm}, 15$ and $20 \mathrm{~mm}$. The tensile strength increased from $5 \mathrm{~mm}$ to $15 \mathrm{~mm}$ length that is from $42 \mathrm{MPa}$ to $62 \mathrm{MPa}$ but showed a decreased in subsequent fibre lengths up to $25 \mathrm{~mm}$. Young's modulus increased with fibre length showed its maximum value at $15 \mathrm{~mm}$ fibre length which was $653.04 \mathrm{MPa}$. It dips to $641.93 \mathrm{MPa}$ at $25 \mathrm{~mm}$ showing a decrease.

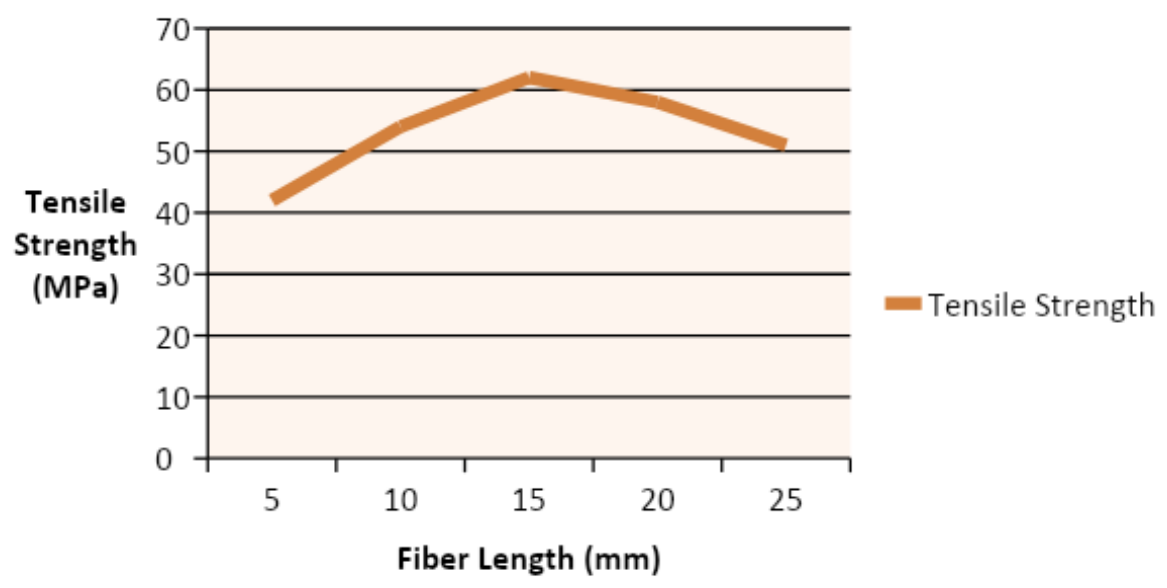

Figure 8: Effect of Banana Fibre Length on Tensile Strength of Epoxy Biocomposite.

- Sharath et.al [13] used coir and wild date palm as fibre reinforcements on the epoxy resin and studied the effect of fibre length on the mechanical properties of the biocomposite. Date palm was selected as reinforcement because of its low density and higher young modulus. The fibres were dipped in a $5 \% \mathrm{NaOH}$ solution for alkaline treatment for $1 \mathrm{~h}$ after which they were washed with $1 \% \mathrm{HCl}$ solution to neutralize the fibres. There was increase in the impact strength with fibre length and impact strength for fibre length $15 \mathrm{~mm}$ was $6.41 \mathrm{KJ} / \mathrm{m}^{2}$, being the 
maximum.

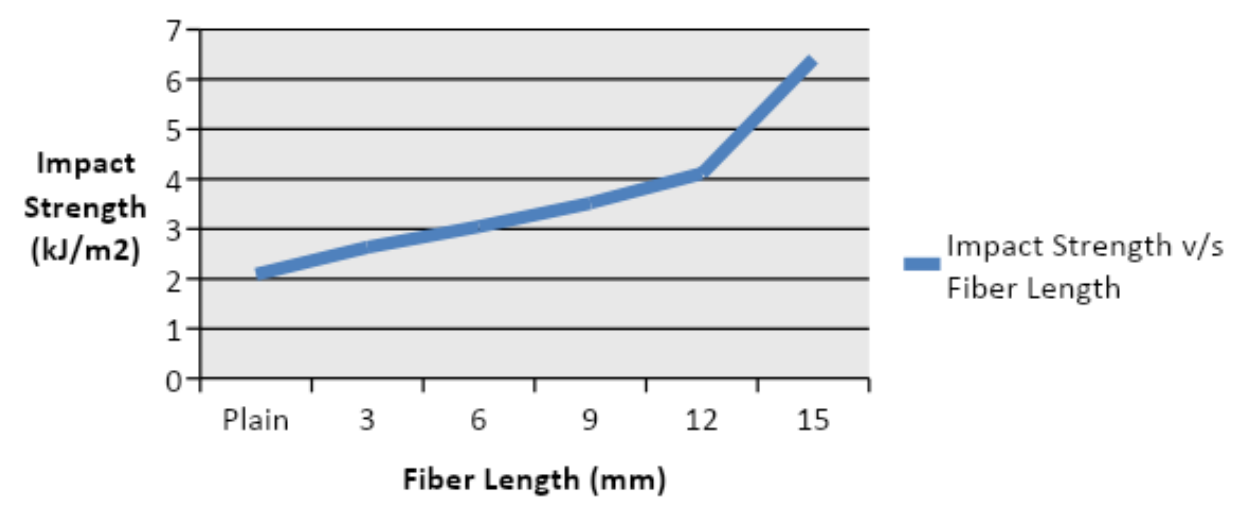

Figure 9: Effect of Coir and Date Palm Fibre Length on the Impact Strength of the Biocomposite.

\section{METHODOLOGY}

A comprehensive literature review was conducted in order to determine the effects of the fiber content and fiber length on the mechanical properties of the biocomposites such tensile strength, tensile modulus, flexural strength and flexural modulus. A consolidated review of these two processing parameters was presented because of dearth of technical reviews involving these two parameters. Most of the review entirely focused on one of the above two parameters. The reason these two parameters were selected was because of availability of individual literature on each of them and because of their frequent usage in the fabrication of the biocomposites.

It is important to note that only these two parameters do not necessarily impact the performance of the biocomposites. Other key factors such as matrices, fabrication methods, interfacial strength, fiber dispersion and density also determine the extent of variation in the mechanical properties. Therefore, it becomes imperative for the other authors to work on these parameters too and develop a fully fledged consolidate review of the same.

\section{RESULTS AND DISCUSSIONS}

By conducting this review, we can develop insights regarding why and how fiber content and fiber length affect the mechanical properties of the biocomposite. This could further help the manufactures to alter the abovementioned parameters accordingly in order to develop a product that is both environmentally sustainable and industrially robust.

\section{Why Changing the Magnitude of Fibre Content alters Mechanical Properties?}

Following are the possible reasons for changing values of mechanical properties:

- As the fibre content increased, the mechanical properties such tensile strength and tensile modulus also increased gradually to particular limit. This increase in the tensile properties could be attributed to the physical and mechanical properties of the reinforcement fibres themselves.

- Most significant is the impact of wettability of the fibres with polymer resin. The more adequate the wetting of the reinforcing fibres by the polymers, better the bonding the between the two. This leads to increase interfacial strength which is reflected by increase in the Tensile strength, tensile modulus, flexural strength and flexural 
modulus of changing the Fibre Content.

- Fiber pullouts are responsible for the early dip in mechanical properties. Short fibers are usually prone to fiber pullouts. Fiber pullouts which usually occur on crack propagation can also be prevented if long and more fibers in volume are used.

\section{Why Changing the Magnitude of Fibre Length alters Mechanical Properties?}

Following conclusions can be drawn henceforward which represent the effect of fibre length on the mechanical properties of the biocomposites:

- Fibre pullout and fibre bridging are dependent on the fibre length [14] (Dassois).

- More the fibre length, more the probability of fibre pullout and thus fibre bridging.

- Short length fibres easily disperse in the polymer resin thereby preventing any possibility of crack propagation and thus fibre bridging.

- It was observed in most of the cases that upon increasing the fiber length, tensile strength, tensile modulus, flexural strength and flexural modulus all showed a gradual increase. This could be attributed to more fiber bridging because of the long continuous fibers present in matrix.

\section{CONCLUSIONS}

In case of the fibre content, it was observed that a gradual change in fibre content produced a shift in the mechanical properties of the biocomposite.. This was due to the good interfacial adhesion between the matrices and reinforcement fibres as well as the physic-mechanical properties of the bio-fibres.

For the fibre length, a direct impact on the tensile, flexural and impact strengths was observed. Two primary mechanisms responsible for either enhancing or decrementing the mechanical properties when fibre lengths were altered were: fibre pullouts and fibre bridging.

Therefore, it is necessary to more intensively evaluate the effect of the each processing parameters and design the product accordingly to achieve maximum utility and enhanced performance. Biocomposites are the key to next phase of green manufacturing and hence should be given their due importance in the coming years.

\section{ACKNOWLEDGEMENTS}

I wish to express my profound gratitude and indebtedness to Prof. Rajiv Chaudhary, Department of Mechanical Engineering, Delhi Technological University, Delhi-110042 for introducing the present topic and for his inspiring guidance, constructive criticism and valuable suggestion throughout in conducting this review work.

\section{REFERENCES}

1. Faruk, O., Biocomposites reinforced with natural fibres: 2000-2010. Progress in Polymer Science, 1552-1596, (2012).

2. F. Sarasini, V. Fiore, A systematic literature review on less common natural fibres and their biocomposites, Journal of Cleaner Production (2018), doi:10.1016/j.jclepro.2018.05.197

3. Patel, Brijesh Kumar, et al. "Development of fly ash based new biocomposites material as wood substitute." International Journal of Mechanical and Production Engineering Research and Development (IJMPERD) (2017): 1-6. 
4. Bajpai, Pramendra Kumar, et al. "Processing and characterization of bio-composites." Handbook of Ecomaterials (2017): 118.

5. Mittal, Mohit, and Rajiv Chaudhary. "Factors Affecting the Performance of Biocomposite: A Review." (2017).

6. Kumar, P. Manoj, et al. "Development And Study of Tribological Properties of Biocomposite For Brake Pad Application." Int. J. Mechan. Product. Eng. Res. Dev. 7.6 (2017).

7. Ranganathan, Nalini, et al. "Structure property relation of hybrid biocomposites based on jute, viscose and polypropylene: The effect of the fibre content and the length on the fracture toughness and the fatigue properties." Composites Part A: Applied science and manufacturing 83 (2016): 169-175.

8. Mohanty, A. K., et al. "Effect of process engineering on the performance of natural fiber reinforced cellulose acetate bio composites." Composites Part A: applied science and manufacturing 35.3 (2004): 363-370.

9. Costa, A. F. S., Maria Alice Vasconcelos Rocha, and L. A. Sarubbo. "Bacterial cellulose: an ecofriendly biotextile." International Journal of Textile and Fashion Technology 7 (2017): 11-26.

10. Liu, Wanjun, et al. "Green'composites from soy based plastic and pineapple leaf fiber: fabrication and properties evaluation." Polymer 46.8 (2005): 2710-2721.

11. Sawpan, Moyeenuddin A., Kim L. Pickering, and Alan Fernyhough. "Improvement of mechanical performance of industrial hemp fibre reinforced polylactide biocomposites." Composites Part A: Applied Science and Manufacturing 42.3 (2011): 310 319.

12. Mittal, Mohit, and Rajiv Chaudhary. "Experimental investigation on the mechanical properties and water absorption behavior of randomly oriented short pineapple/coir fiber-reinforced hybrid epoxy composites." Materials Research Express 6.1 (2018): 015313.

13. Naveen, P. N. E., and M. Yasaswi. "Experimental analysis of coir-fiber reinforced polymer composite materials." International Journal of Mechanical Engineering and Robotics Research 2.1 (2013): 10-18.

14. Sathyamoorthy, G., and S. Raja Narayanan. "Experimental Analysis of Delamination Failure in Jute-Coir Fiber Reinforced Composites." International Journal of Mechanical and Production Engineering Research and Development (IJMPERD) ISSN (P) (2018): 2249-6890.

15. Thirmizir, MZ Ahmad, et al. "Kenaf $\square$ bast $\square$ fiber $\square$ filled biodegradable poly (butylene succinate) composites: Effects of fiber loading, fiber length, and maleated poly (butylene succinate) on the flexural and impact properties." Journal of Applied Polymer Science 122.5 (2011): 3055-3063.

16. Sumaila, M., I. Amber, and M. Bawa. "Effect of fiber length on the physical and mechanical properties of random oreinted, nonwoven short banana (musa balbisiana) fibrelepoxy composite." Cellulose 62 (2013): 64.

17. GP, Sharath, B. S. Kishor, and Vinod B. Naveen Ankegowda. "Effect of Fiber Length on the Mechanical Properties of Coir and Wild Date Palm Reinforced Epoxy Composites."

18. Dassios, Konstantinos G. "A review of the pull-out mechanism in the fracture of brittle-matrix fibre-reinforced composites." Advanced composites letters 16.1 (2007): 096369350701600102. 

